\title{
Factors Associated with End-of-Life Health Service Use in Patients Dying of Cancer
}

\section{Facteurs associés à l'utilisation des soins en fin de vie pour les patients mourant du cancer}

\author{
by LISA BARBERA, MD \\ Radiation Oncologist, Odette Cancer Centre \\ Adjunct Scientist, Institute for Clinical Evaluative Sciences \\ Assistant Professor, Department of Radiation Oncology, University of Toronto \\ Toronto, ON
}

JONATHAN SUSSMAN, MD

Radiation Oncologist, Juravinski Regional Cancer Centre

Associate Director of the Supportive Cancer Care Research Unit, Juravinski Cancer Centre Associate Professor, Department of Oncology, McMaster University

Hamilton, $\mathrm{ON}$

RAYMOND VIOLA, MD

Division of Cancer Care and Epidemiology, Queen's Cancer Research Institute Palliative Care Physician, Southeastern Ontario Health Sciences Complex Assistant Professor, Department of Medicine, Queen's University Kingston, $\mathrm{ON}$ 
AMNA HUSAIN, MD

Palliative Care Physician, Temmy Latner Centre for Palliative Care

Assistant Professor, Department of Community and Family Medicine, University of Toronto Toronto, ON

DORIS HOWELL, RN, PHD

RBC Financial Group Chair in Oncology Nursing Research, University Health Network Assistant Professor, Faculty of Nursing, University of Toronto

Toronto, ON

S. LAWRENCE LIBRACH, MD

Gifford-Jones Professor, Pain Control and Palliative Care

Professor, Department of Community and Family Medicine, University of Toronto Toronto, ON

HUGH WALKER, PHD

Adjunct Professor, Departments of Oncology and Community Health and Epidemiology

Queen's University

Kingston, ON

RINKU SUTRADHAR, PHD

Biostatistician, Institute for Clinical Evaluative Sciences

Toronto, ON

CAROLE CHARTIER, MSC

Programmer and Biostatistician, Sunnybrook Health Sciences Centre Toronto, ON

LAWRENCE PASZAT, MD

Senior Scientist, Institute for Clinical and Evaluative Sciences

Associate Professor, Departments of Radiation Oncology and Health Policy,

Management \& Evaluation, University of Toronto

Toronto, ON 


\section{Abstract}

This study describes acute care hospital death, physician house calls and home care near the end of life among patients who died of cancer and the factors that are associated with these events and services. It is a population-based retrospective study that uses linked administrative healthcare data. The cohort includes all patients who died of cancer between 2000 and 2004 in Ontario, Canada.

Fifty-five per cent of patients died in acute care hospital, $68 \%$ received home care in the last 6 months of life and 24\% received at least one physician house call in the last 2 weeks of life. Increased age was associated with a decreased likelihood of each event or service. Women were less likely to die in acute care and more likely to receive home care. Residents in low-income neighbourhoods were less likely to receive house calls or home care. Patients who received home care or house calls were less likely to die in acute care.

Our observations add to those in the literature, suggesting a need to increase the use of supportive care services at the end of life in hopes of decreasing the need for acute care. They also serve as a baseline for future comparison, which is of particular interest since new government policies directed at end-of-life care were recently introduced.

\section{Résumé}

Cette étude décrit la mortalité dans les hôpitaux de soins de courte durée, les visites à domicile des médecins et les soins à domicile vers la fin de vie parmi les patients qui sont mort du cancer. L'étude examine également les facteurs associés à ces événements et à ces services. Il s'agit d'une étude rétrospective fondée sur la population, qui emploie des données administratives couplées. Le groupe étudié comprend tous les patients qui sont morts du cancer entre 2000 et 2004, en Ontario, au Canada.

Cinquante-cinq pour cent des patients sont décédés dans un hôpital de soins de courte durée, $68 \%$ ont reçu des soins à domicile dans les derniers six mois de leur vie et $24 \%$ ont reçu au moins une visite à domicile d'un médecin au cours des deux dernières semaines de leur vie. La probabilité de chacun de ces événements ou services décroît en fonction de lâge. Les femmes sont moins susceptibles de décéder dans un établissement de soins de courte durée et plus susceptibles de recevoir des visites à domicile. Les résidents des quartiers à faible revenu sont moins susceptibles de recevoir des visites ou des soins à domicile. Les patients qui ont reçu des visites ou des soins à domicile sont moins susceptibles de décéder dans un établissement de soins de courte durée.

Nos observations s'ajoutent à celles de la littérature et font voir le besoin d'accroître l'utilisation des soins de soutien en fin de vie, dans le but de diminuer l'utilisation des soins de courte durée. Nos observations servent également de point de comparaison 
pour des études à venir, ce qui présente un intérêt particulier étant donné la mise en place récente de politiques gouvernementales visant les soins en fin de vie.

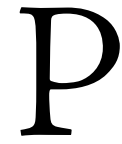
ALLIATIVE CARE IS AN IMPORTANT PART OF THE CANCER CARE CONTINUUM because it aims to enhance quality of life at the end of life (Ferris et al. 2002). However, researchers and policy makers have pointed to severe deficiencies in the provision of palliative care in Canada as well as the United States, United Kingdom and European Union (Romanow 2002; Kirby and LeBreton 2002; Cancer Quality Council of Ontario 2003; Carstairs and Beaudoin 2000; Institute of Medicine 2001; Centeno et al. 2007; Addington-Hall et al. 2003; Canadian Strategy for Cancer Control 2002).

A description of the healthcare services used by cancer patients in the time leading up to death can provide valuable information to decision-makers about the use of acute care services (such as admission to hospital) compared to services that reflect a more palliative or supportive approach (including home visits from physicians or nurses). Knowing which services patients receive before death offers insight into whether or not they are accessing resources meant to improve quality of dying (Patrick et al. 2003).

The literature suggests that care may be growing more aggressive near the end of life over time (Earle et al. 2004). There is also a discrepancy between what patients report as their preferred place of death (most often home) and actual place of death (Beccaro et al. 2006; Bruera et al. 2003; Burge et al. 2003; Foreman et al. 2006; Gilbar and Steiner 1996; Karlsen and Addington-Hall 1998; McWhinney et al. 1995; Heyland et al. 2000; Pritchard et al. 1998). People who die in institutions such as acute care facilities have unmet needs for symptom control, physician communication, emotional support and respectful treatment compared with those receiving patientcentred palliative care services at home (Teno et al. 2004).

Existing research describes either the use of one particular service (e.g., house calls or emergency room visits) or a number of services for one specific type of cancer. The purpose of this study is to describe a range of outcomes, specifically death in acute care bed, home care and physician house calls for patients who died of any type of cancer in Ontario, Canada. The study also describes the factors that are associated with each of these outcomes.

\section{Methods}

This is a retrospective study that uses administrative sources of healthcare data. All residents of Ontario are covered by a government-provided healthcare plan. All services described in this study are government funded. 


\section{Data sources}

The Ontario Cancer Registry (OCR) is a comprehensive population-based cancer registry created to capture all incident cases of cancer in the province (Clarke et al. 1991; Robles et al. 1988). The Ontario Health Insurance Plan (OHIP) is a database that contains all medicare billing claims by physicians in the province. The Canadian Institute for Health Information (CIHI) Discharge Abstract Database (DAD) lists diagnostic and procedure codes from all in-patient and outpatient hospital admissions. The Ontario Home Care Administrative System (OHCAS) captures records of every referral for home care and all home care visits to Ontario residents. In Ontario, home care most commonly refers to nursing or personal support worker services. The Registered Persons Database (RPDB) contains demographic information on all residents of Ontario who are eligible for OHIP. Canada's 2001 Census provides neighbourhood income quintiles for this study.

\section{Case ascertainment}

We used the Ontario Cancer Registry (OCR) to identify all patients who died of cancer between 2000 and 2004, as indicated by the death certificate. If more than one cancer was registered in OCR, the registration record that matched the cause of death was chosen. Cases were excluded if (a) a cancer diagnosis had not been made prior to death, (b) the death occurred within 30 days of a major cancer-related operative procedure, $(c)$ the health insurance number was invalid during the last six months of life, (d) the patient died outside Ontario or (e) the patient was younger than 20 years of age. These criteria were meant to identify patients who might have been eligible for palliative care: they were diagnosed with cancer prior to their death and died of cancer, not a complication from cancer surgery or some other cause.

Cases were linked to the other data sets using a common unique identifier to evaluate health services use in the end-of-life period.

\section{Patient variable definitions}

\section{AGE AT DEATH}

We used date of birth from RPDB and date of death from OCR to calculate age at death.

\section{GENDER}

As per OCR. 


\section{CANCER CAUSE OF DEATH}

The ICD 9 codes (OCR) were grouped as follows: head and neck: 140-149, 160, 161; breast: 174; lung: 162; prostate: 185 ; ovary: 183 ; colorectal: 153, 154; CNS: 191; lymphoma/leukemia: 200-208; other GU/gyn: 179-182, 184, 186-189; melanoma/sarcoma: 170-172; non-melanoma skin cancer: 173; other GI: 150-152, 155-159; metastases: 196-199; other: 163-165, 190, 192-194.

\section{CO-MORBIDITY}

We used diagnoses coded in CIHI in the last six months of life to capture co-morbid illness in order to calculate the Deyo modification of the Charlson score (Deyo et al. 1992) with scores for primary and metastatic cancer subtracted.

\section{REGION}

Patients were assigned to regions as per RPDB data, using their place of residence rather than where they received care. The province of Ontario is divided into 14 local health regions based on patterns of tertiary referral (Ontario MoHLTC 2007).

\section{RURAL}

We used the postal code from RPDB to categorize patients by residence in a rural or non-rural part of Ontario. Rural is considered to include rural and small towns and municipalities outside the commuting zone of larger urban centres (i.e., a population of 10,000 or more) and is constructed from census subdivisions (Statistics Canada 1994).

\section{INCOME QUINTILE}

We linked data from Canada's 2001 Census with postal code from RPDB using a postal code conversion file to construct community income quintiles (Wilkins 2001).

\section{Outcomes}

DEATH IN AN ACUTE CARE BED

The discharge disposition variable from CIHI-DAD was used to identify location of death in acute care. Re-abstraction studies indicate 98\%-99\% agreement for this variable (CIHI 2004). 
HOME CARE IN THE LAST SIX MONTHS OF LIFE

We designated a patient as receiving home care if the patient had any record of service in the last six months of life. This method captures patients actually receiving service and would not count patients who are referred but never seen. Six months is a commonly used time-frame to describe health services use at the end of life (Huang et al. 2002) and was felt to be a clinically relevant period for initiating such a service.

\section{HOUSE CALLS IN THE LAST TWO WEEKS OF LIFE}

OHIP fee codes indicating a house call or premium for care provided in the home by a physician were used to designate house calls as long as there was no pronouncement of death billed on the same service date. A pronouncement code together with a code for care in the home was interpreted as a house call for pronouncing death. Patients who were in hospital for the entire last two weeks of life were excluded from the denominator, since they would be unable to receive a house call. Two weeks is a clinically relevant time-frame for this outcome. House calls are resource intensive, and care in Ontario is most commonly provided in an ambulatory setting for as long as possible.

\section{Analysis}

Using descriptive statistics, the population is described with respect to age, gender, type of cancer, co-morbidity, year of death, income quintile, rural residence and region. The population crude proportions are computed for each outcome. Trends over time for each outcome are examined with the Cochrane Armitage trend test. Age- and sex-adjusted regional rates for each service are calculated using direct standardization according to the 1991 Canadian population. The ratio of the highest and lowest regional rates is presented.

Logistic regression models for each outcome are constructed with the following independent variables: age, gender, neighbourhood income quintile, rural residence, type of cancer, co-morbidity and region. For the outcome of acute care death, we decided a priori to add home care and house calls to the model as well. Co-linearity was examined between house calls and home care using the phi coefficient to measure the degree of association between the binary variables. For the outcome of house calls we decided a priori to add home care to the model.

Possible confounding between age and home care is explored for the outcomes of acute care death and house calls. We also examine whether house calls confound the association between income and acute care death. Upon establishing the main effects model, interactions between age and gender, as well as between home care and house calls, are also investigated. 


\section{Results}

The final cohort consists of 112,398 patients who died of cancer in Ontario between 2000 and 2004. Patients in the following categories (numbers provided in parentheses) are excluded: no cancer diagnosis prior to death (0); the death occurred within 30 days of a major cancer-related operative procedure $(1,581)$; invalid health insurance number (14,347); death outside Ontario (649); younger than 20 years of age (387). Table 1 lists descriptions of the final cohort of patients.

TABLE 1. Description of patients in cohort $(N=|| 2,398)$

\begin{tabular}{|l|l|}
\hline Age & $\mathbf{N}(\%)$ \\
\hline Median (range) & \\
\hline$<50$ & $73(20-108)$ \\
\hline $50-69$ & $7,430(7 \%)$ \\
\hline 270 & $38,275(34 \%)$ \\
\hline Year of death & $66,693(60 \%)$ \\
\hline 2000 & \\
\hline 200 I & $21,744(19 \%)$ \\
\hline 2002 & $22,244(20 \%)$ \\
\hline 2003 & $22,489(20 \%)$ \\
\hline 2004 & $22,821(20 \%)$ \\
\hline Sex & $23,070(21 \%)$ \\
\hline Female & \\
\hline Male & $53,225(47 \%)$ \\
\hline Cancer & $59,173(53 \%)$ \\
\hline Lung & $10,929(10 \%)$ \\
\hline Other gastrointestinal & $9,099(8 \%)$ \\
\hline Colorectal & $8,851(8 \%)$ \\
\hline Lymphoma/Leukemia & $17,938(16 \%)$ \\
\hline Breast & $11,457(10 \%)$ \\
\hline Metastatic cancer NOS & \\
\hline Other genitourinary/gyn & \\
\hline Prostate & $(7 \%)$ \\
\hline
\end{tabular}


Factors Associated with End-of-Life Health Service Use in Patients Dying of Cancer

TABLE 1. Continued

\begin{tabular}{|c|c|}
\hline Ovary & $2,906(3 \%)$ \\
\hline Head and neck & $2,766(2 \%)$ \\
\hline Melanoma/Sarcoma & $2,476(2 \%)$ \\
\hline Central nervous system & $2,462(2 \%)$ \\
\hline Other & ।,375 (1\%) \\
\hline \multicolumn{2}{|l|}{ Co-morbidity } \\
\hline High & $17,428(16 \%)$ \\
\hline Low & $94,970(85 \%)$ \\
\hline \multicolumn{2}{|l|}{ Income quintile } \\
\hline I (low) & $23,780(22 \%)$ \\
\hline 2 & 24,221 (22\%) \\
\hline 3 & $21,462(20 \%)$ \\
\hline 4 & 19,084 (I8\%) \\
\hline 5 (high) & $19,530(18 \%)$ \\
\hline \multicolumn{2}{|l|}{ Rural residence } \\
\hline No & $94,568(84 \%)$ \\
\hline Yes & $17,767(16 \%)$ \\
\hline \multicolumn{2}{|l|}{ Region } \\
\hline Erie-St. Claire & $6,836(6 \%)$ \\
\hline Southwest & $9,69 \mid(9 \%)$ \\
\hline Waterloo-Wellington & $5,646(5 \%)$ \\
\hline Hamilton-Niagara-Haldimand-Brant & |4,850 (13\%) \\
\hline Central West & $3,960(4 \%)$ \\
\hline Mississauga-Halton & $6,702(6 \%)$ \\
\hline Toronto & $10,660(10 \%)$ \\
\hline Central & $10,617(9 \%)$ \\
\hline Central East & |2,565 ( 1 \%) \\
\hline Southeast & $5,869(5 \%)$ \\
\hline Champlain & $10,74 \mid(10 \%)$ \\
\hline North Simcoe-Muskoka & $4,408(4 \%)$ \\
\hline Northeast & $6,977(6 \%)$ \\
\hline Northwest & $2,584(2 \%)$ \\
\hline
\end{tabular}


Table 2 indicates the crude proportion of patients who experienced each outcome. All outcomes show a statistically significant trend over time. Most of these changes are of small magnitude. The proportion of patients receiving home care in the last two weeks was 52\%. The median number of visits was 31 in the last six months and 13 in the last two weeks. The proportion of patients receiving a house call in the last six months was 33\%. The median number of house calls in the last six months was three, and in the last two weeks was two. The proportion of acute care deaths that occurred on a palliative care service was approximately $11 \%$.

TABLE 2. Outcome by year, 2000-2004, across province (crude rates)

\begin{tabular}{|l|l|l|l|l|l|l|l|}
\hline Outcome & $\begin{array}{l}\mathbf{2 0 0 0} \\
\mathbf{( n = 2 1 , 7 7 4 )}\end{array}$ & $\begin{array}{l}\mathbf{2 0 0 I} \\
(\mathbf{n = 2 2 , 2 4 4 )}\end{array}$ & $\begin{array}{l}\mathbf{2 0 0 2} \\
\mathbf{( n = 2 2 , 4 8 9 )}\end{array}$ & $\begin{array}{l}\mathbf{2 0 0 3} \\
(\mathbf{n = 2 2 , 8 2})\end{array}$ & $\begin{array}{l}\mathbf{2 0 0 4} \\
\mathbf{( n = 2 3 , 0 7 0 )}\end{array}$ & $\begin{array}{l}\text { All years } \\
\mathbf{( N = 1 1 2 , 3 9 8 )}\end{array}$ & $\begin{array}{l}\text { Cochrane- } \\
\text { armitage } \\
\text { trend test }\end{array}$ \\
\hline $\begin{array}{l}\text { Death in acute } \\
\text { care hospital }\end{array}$ & $56.4 \%$ & $56.1 \%$ & $56.3 \%$ & $53.4 \%$ & $53.1 \%$ & $55.0 \%$ & $p<0.0001$ \\
\hline $\begin{array}{l}\text { Home care } \\
\text { in the last 6 } \\
\text { months of life }\end{array}$ & $71.4 \%$ & $69.2 \%$ & $65.1 \%$ & $68.3 \%$ & $66.5 \%$ & $68.1 \%$ & $p<0.0001$ \\
\hline $\begin{array}{l}\text { House calls } \\
\text { in the last 2 } \\
\text { weeks of life }\end{array}$ & $27.3 \%$ & $24.6 \%$ & $23.0 \%$ & $23.2 \%$ & $21.7 \%$ & $23.9 \%$ & $p<0.0001$ \\
\hline
\end{tabular}

${ }^{a}$ Denominator excludes those in hospital the entire last 2 weeks of life $(n=20,09$ I)

The ratio of the highest and lowest age-sex adjusted health region rates is presented in Table 3. Greatest variation was seen for house calls and least for home care. Region was a significant variable in the logistic regression model described below $(p<0.0001)$.

TABLE 3. Minimum and maximum age-sex adjusted regional proportions of each outcome

\begin{tabular}{|l|l|l|l|l|}
\hline & $\begin{array}{l}\text { Minimum } \\
\text { proportion }\end{array}$ & $\begin{array}{l}\text { Maximum } \\
\text { proportion }\end{array}$ & $\begin{array}{l}\text { Absolute } \\
\text { difference }\end{array}$ & ratio \\
\hline Acute care death & $45.4 \%$ & $63.3 \%$ & $17.9 \%$ & 1.4 \\
\hline House calls 2 weeks & $9.5 \%$ & $38.3 \%$ & $28.8 \%$ & 4.0 \\
\hline Home care 6 months & $59.1 \%$ & $73.3 \%$ & $14.2 \%$ & 1.2 \\
\hline
\end{tabular}


Table 4 summarizes the results of the adjusted logistic regression models for each outcome. In addition to the variables reported in the tables, the models included cancer type, rural residence, co-morbidity and region. There was no co-linearity between house calls and home care (phi coefficient value 0.257 ). No confounding was detected.

TABLE 4. Results of regression modelling for each outcome, selected variables

\begin{tabular}{|c|c|c|c|c|c|c|}
\hline \multirow[b]{2}{*}{ Variable } & \multicolumn{2}{|c|}{$\begin{array}{l}\text { Death in acute care } \\
\text { bed }\end{array}$} & \multicolumn{2}{|c|}{$\begin{array}{l}\text { House calls in last } 2 \\
\text { weeks }\end{array}$} & \multicolumn{2}{|c|}{$\begin{array}{l}\text { Home care in last } 6 \\
\text { months }\end{array}$} \\
\hline & Adj OR & $95 \% \mathrm{Cl}$ & Adj OR & $95 \% \mathrm{Cl}$ & Adj OR & $95 \% \mathrm{Cl}$ \\
\hline \multicolumn{7}{|l|}{ Age } \\
\hline$<50$ & 1 & & 1 & & 1 & \\
\hline $50-69$ & 0.88 & $(0.83,0.94)$ & 0.93 & $(0.87,1.00)$ & 0.79 & $(0.74,0.84)$ \\
\hline$\geq 70$ & 0.69 & $(0.65,0.73)$ & 0.84 & $(0.79,0.90)$ & 0.56 & $(0.53,0.59)$ \\
\hline \multicolumn{7}{|l|}{ Gender } \\
\hline Male & I & & I & & I & \\
\hline Female & 0.88 & $(0.85,0.91)$ & 0.97 & $(0.93,1.00)$ & 1.15 & $(1.12,1.18)$ \\
\hline \multicolumn{7}{|c|}{$\begin{array}{l}\text { Neighbourhood } \\
\text { income quintile }\end{array}$} \\
\hline I & 1.10 & $(1.05,1.15)$ & 0.62 & $(0.59,0.67)$ & 0.82 & $(0.79,0.86)$ \\
\hline 2 & 1.11 & $(1.06,1.15)$ & 0.72 & $(0.68,0.75)$ & 0.88 & $(0.85,0.92)$ \\
\hline 3 & 1.08 & $(1.03,1.12)$ & 0.77 & $(0.73,0.81)$ & 0.93 & $(0.89,0.97)$ \\
\hline 4 & 1.05 & $(1.00,1.10)$ & 0.81 & $(0.77,0.86)$ & 0.96 & $(0.92,1.01)$ \\
\hline 5 (high) & I & & I & & I & \\
\hline \multicolumn{7}{|c|}{$\begin{array}{l}\text { Home care in last } 6 \\
\text { months }\end{array}$} \\
\hline No & 1 & & 1 & & $\begin{array}{l}\text { Not } \\
\text { tested }\end{array}$ & \\
\hline Yes & 0.57 & $(0.55,0.58)$ & 6.49 & $(6.16,6.84)$ & & \\
\hline \multicolumn{7}{|c|}{$\begin{array}{l}\text { House call in last } 2 \\
\text { weeks }\end{array}$} \\
\hline No & I & & Not tested & & $\begin{array}{l}\text { Not } \\
\text { tested }\end{array}$ & \\
\hline Yes & 0.27 & $(0.26,0.28)$ & & & & \\
\hline
\end{tabular}

Significant results shown in bold. 
The oldest age group (when compared to the youngest) was less likely to die in acute care or to receive home care or house calls. Women were less likely to die in acute care and more likely to receive home care, compared to men. Individuals living in neighbourhoods with the lowest income quintiles were less likely to receive house calls or home care.

The use of home care or house calls was associated with decreased odds of death in acute care. Home care was associated with increased odds of receiving house calls.

The acute care death model, which included physician house calls in the last two weeks as an input variable, was also re-run, excluding the 20,091 patients who were in hospital throughout the last two weeks of life. This exclusion did not substantially change the results (data not shown).

In separate models we evaluated interactions between age and sex, and home care and house calls. For the outcome acute care death, the parameter estimate of the agesex interaction effect was significant $(p<0.001)$ for women over 70 years of age. There was no significant age-sex interaction for any of the other outcomes.

There were interaction effects between house calls and home care for acute care death. Patients who had house calls in the last two weeks of life were $62 \%(\mathrm{OR}=0.38$, 95\% CI 0.34-0.43) less likely to die in hospital if they also had home care in the last six months than if they had no home care. Patients who had home care were $75 \%$ $(\mathrm{OR}=0.25,95 \% \mathrm{CI} 0.24-0.26)$ less likely to die in hospital if they also had house calls than if they had no house calls.

\section{Discussion}

\section{Key findings}

Our study describes three key outcomes for cancer patients near the end of life. Deaths in an acute care bed may be decreasing over time, but so are physician house calls and home care visits. Increased age was associated with a decreased likelihood of each outcome. Women are less likely to die in acute care and more likely to receive home care. Patients living in neighbourhoods with the lowest income quintile are least likely to receive services in the home. Patients who do receive home care or house calls are much less likely to die in acute care.

\section{Strengths and limitations}

One of the strengths of this study is its comprehensiveness. Unlike similar studies conducted in the United States, our cohort includes all adult patients, not only those over the age of 65 who are enrolled in medicare (Earle et al. 2004). Unlike some Canadian studies (Burge et al. 2005; Gagnon et al. 2004), we include all cancer diag- 
noses to provide a global picture relevant for policy and planning. We include institutional and community care settings. Our cohort is from the new millennium and is population-based.

Creating a decedent cohort to retrospectively evaluate services used in a time window prior to death has been criticized (Bach et al. 2004) and defended (Earle and Ayanian 2006; Teno and Mor 2005; Barnato and Lynn 2005) as a method to study end-of-life care. Both sides agree that this approach is reasonable to describe events very close to death (six months is close to death and two weeks is even closer), as used in the present study. A recent study has confirmed this approach (Setoguchi et al. 2008).

As with many studies relying on administrative sources of healthcare data, some of the services identified in the administrative data have not been validated with chart review data. The discharge disposition variable in CIHI-DAD has been validated and is accurate (CIHI 2004). House call claims have not been validated, but when physicians provide this service they are able to claim an additional premium, and it is to their advantage to submit complete billings for all services provided. The home care data have not been validated, and the concerns about data quality for this data set suggest that our estimates may underestimate home care use.

\section{Other findings from the literature}

Our study finding that $55 \%$ of cancer patients in Ontario die in an acute care bed compares favourably with other Canadian provinces. Seventy per cent of breast cancer patients in Quebec (Gagnon et al. 2004) and 74\% of patients in Nova Scotia (Burge et al. 2003) die in acute care. Acute care death rates have been reported in the range of 30\% to 35\% in the United States (Earle et al. 2004; Flory et al. 2004) and between 35\% and 56\% in Europe (Beccaro et al. 2006; Aabom et al. 2006; Cohen et al. 2006). Death in hospital from any cause (not just cancer) occurs in $45 \%$ to $55 \%$ of patients in Western Canada (CIHI 2007) and is reported to be decreasing over time nationwide (Wilson et al. 2009). In Ontario we observed 33\% of patients receiving a house call in the last six months of life, a percentage similar to other Canadian studies reporting $21 \%$ and $45 \%$ for this outcome (Gagnon et al. 2004; Burge et al. 2005). We are unaware of comparable data for home care in cancer patients.

Our study found that all three outcomes were less likely with increasing age, and that women were less likely to die in hospital and more likely to receive home care. Results in the literature regarding the association with age or gender and end-of-life services are conflicting (Burge et al. 2003, 2008; Earle et al. 2004; Grande et al. 1998; Bruera et al. 2002; Gomes and Higginson 2006). Our finding that low neighbourhood income quintile is associated with fewer patients receiving house calls or home care is consistent with similar studies in cancer (Grande et al. 1998; Burge et al. 2005; Huang et al. 2002). 
Studies pertaining to location of death have found that use of home care and an increased intensity of home care are associated with home death (Gomes and Higginson 2006). Randomized clinical trials comparing integrated multidisciplinary palliative care with existing regional services report improved satisfaction (Grande et al. 2000; Hughes et al. 1992; Kane et al. 1984; Brumley et al. 2007), improved symptom control (Rabow et al. 2004), decreased use of acute care services (Jordhoy et al. 2000; Zimmer et al. 1985; Brumley et al. 2007) and decreased cost (Raftery et al. 1996; Brumley et al. 2007) in the intervention arm. Non-randomized studies draw similar conclusions (Bruera et al. 1999). Two of the randomized trials reporting a decrease in in-hospital deaths had physician home visits as part of the intervention (Zimmer et al. 1985; Jordhoy et al. 2000). Other studies have also emphasized that physician home visits are crucial in providing home palliative care (Cherin et al. 2004; Aabom et al. 2005). Our data add to the evidence by showing that patients receiving home care or house calls are much less likely to die in hospital.

\section{Policy implications}

Some of the outcomes described in this study have been suggested as valid indicators for evaluating the quality of end-of-life care (Earle et al. 2003, 2004, 2005). Using administrative data in this way is consistent with a previously published quality framework for palliative and end-of-life care (Stewart et al. 1999). The feasibility of measurement in Ontario had been demonstrated (Grunfeld et al. 2006), and some of these measures have been used as indicators to evaluate health services at the end of life (Barbera et al. 2005, 2006; Cancer Care Ontario 2007).

Our observations, together with those from the literature, suggest a need to increase the use of supportive care services at the end of life in the hope of decreasing the need for acute care. Deploying resources to improve the availability of supportive care services in the community would likely improve the quality of patients death and dying and provide more freedom for patients to die in the setting of their choice.

In 2005 the Ontario Ministry of Health announced a new \$115-million End-ofLife Strategy, targeting the majority of funds to home care (Ontario MoHLTC 2005). In 2006 a provincewide initiative began to document patient symptom scores consistently with a common instrument. Our data provide a comprehensive description of service use prior to these initiatives. Subsequent measurement will determine whether these policy changes have had an impact on health services use at the end of life.

\section{ACKNOWLEDGEMENTS}

Dr. Barbera is supported by a Career Scientist Award from the Ontario Ministry of Health and Long-Term Care. Dr. Paszat receives a clinician scientist salary funded 
by the Ministry of Health and Long-Term Care. This network of researchers is supported by a grant from Cancer Care Ontario.

The authors would like to acknowledge Minh Duong-Hua, MSc (Programming and Biostatistics, Institute for Clinical Evaluative Sciences) for her programming support.

This study was supported by the Institute for Clinical Evaluative Sciences (ICES), which is funded by an annual grant from the Ontario Ministry of Health and LongTerm Care (MoHLTC). The opinions, results and conclusions reported in this paper are those of the authors and are independent from the funding sources. No endorsement by ICES or the Ontario MoHLTC is intended or should be inferred.

Correspondence may be directed to: Lisa Barbera, Department of Radiation Oncology, Odette Cancer Centre, 2075 Bayview Avenue, Toronto, ON M4N 3M5; tel.: 416-480-4974; fax: 416480-6002; e-mail: lisa.barbera@sunnybrook.ca.

\section{REFERENCES}

Aabom, B., J. Kragstrup, H. Vondeling, L.S. Bakketeig and H. Stovring. 2005.“Population-Based Study of Place of Death of Patients with Cancer: Implications for GPs." British Journal of General Practice 55(518): 684-89.

Aabom, B., J. Kragstrup, H. Vondeling, L.S. Bakketeig and H. Stovring. 2006. “Does Persistent Involvement by the GP Improve Palliative Care at Home for End-Stage Cancer Patients?" Palliative Medicine 20(5): 507-12.

Addington-Hall, J., F. Aspinal, R. Hughes, M. Dunckley and I.J. Higginson. 2003. Project to Improve Management of Terminal Illness: Summary of Findings from PROMOTE. London, UK: National Council for Palliative Care.

Bach, P.B., D. Schrag and C.B. Begg. 2004."Resurrecting Treatment Histories of Dead Patients: A Study Design That Should Be Laid to Rest." Journal of the American Medical Association 292(22): 2765-70.

Barbera, L., L. Paszat and C. Chartier. 2005. "Death in Hospital for Cancer Patients: An Indicator of Quality of End-of-life Care." Palliative Medicine 19(5): 435-36.

Barbera, L., L. Paszat and C. Chartier. 2006. "Indicators of Poor Quality Care in End-of-Life Cancer Care in Ontario." Journal of Palliative Care 22(1): 12-17.

Barnato, A.E. and J. Lynn. 2005. "Resurrecting Treatment Histories of Dead Patients." Journal of the American Medical Association 293(13): 1591-92.

Beccaro, M., M. Costantini, R.P. Giorgi, G. Miccinesi, M. Grimaldi and P. Bruzzi. 2006. “Actual and Preferred Place of Death of Cancer Patients. Results from the Italian Survey of the Dying of Cancer (ISDOC)." Journal of Epidemiology \& Community Health 60(5): 412-16.

Bruera, E., C.M. Neumann, B. Gagnon, C. Brenneis, P. Kneisler, P. Selmser and J. Hanson. 1999.

"Edmonton Regional Palliative Care Program: Impact on Patterns of Terminal Cancer Care." Canadian Medical Association Journal 161(3): 290-93. 
Bruera, E., N. Russell, C. Sweeney, M. Fisch and L. Palmer. 2002."Place of Death and Its Predictors for Local Patients Registered at a Comprehensive Cancer Center." Journal of Clinical Oncology 20(8): 2127-33.

Bruera, E., C. Sweeney, N. Russell, J.S. Willey and J.L. Palmer. 2003. "Place of Death of Houston Area Residents with Cancer Over a Two-Year Period." Journal of Pain and Symptom Management 26(1): 637-43.

Brumley, R., S. Enguidanos, P. Jamison, R. Seitz, N. Morgenstern, S. Saito, J. McIlwane, K. Hillary and J. Gonzalez. 2007. "Increased Satisfaction with Care and Lower Costs: Results of a Randomized Trial of In-Home Palliative Care." Journal of the American Geriatric Society 55(7): 993-1000.

Burge, F., B. Lawson and G. Johnston. 2003."Trends in the Place of Death of Cancer Patients, 1992-1997." Canadian Medical Association Journal 168(3): 265-70.

Burge, F.I., B. Lawson and G. Johnston. 2005. "Home Visits by Family Physicians during the End of Life: Does Patient Income or Residence Play a Role?” BMC Palliative Care 4(1): 1.

Burge, F.I., B.J. Lawson, G.M. Johnston and E. Grunfeld. 2008. "A Population-Based Study of Age Inequalities in Access to Palliative Care among Cancer Patients." Medical Care 46(12): 1203-11.

Canadian Institute for Health Information (CIHI). 2004. Data Quality of the Discharge Abstract Database Following the First Year Implementation of ICD-10-CA/CCI. Final Report. Ottawa: Author.

Canadian Institute for Health Information (CIHI). 2007. Health Care Use at the End of Life in Western Canada. Ottawa: Author.

Canadian Strategy for Cancer Control (2002). Palliative Care Working Group Report. Toronto: Author.

Cancer Care Ontario. 2007. Cancer System Quality Index. Retrieved January 8, 2010. <http://csqi. cancercare.on.ca $>$.

Cancer Quality Council of Ontario. 2003. Strengthening the Quality of Cancer Services in Ontario. Toronto: Author.

Carstairs, S. and G.A. Beaudoin. 2000. Quality End-of-Life Care: The Right of Every Canadian. Ottawa: Subcommittee of the Standing Senate Committee on Social Affairs, Science and Technology. Retrieved January 8, 2010. <http://www.parl.gc.ca/36/2/parlbus/commbus/senate/ Com-e/upda-e/rep-e/repfinjun00-e.htm $>$.

Centeno, C., D. Clark, T. Lynch, J. Rocafort, A. Greenwood, L.A. Flores et al. 2007. EAPC Atlas of Palliative Care in Europe. Houston, TX: IAHPC Press.

Cherin, D.A., S.M. Enguidanos and P. Jamison. 2004. "Physicians as Medical Center 'Extenders' in End-of-Life Care: Physician Home Visits as the Lynchpin in Creating an End-of-Life Care System." Home Health Care Services Quarterly 23(2): 41-53.

Clarke, E.A., L.D. Marrett and N. Kreiger. 1991. "Cancer Registration in Ontario: A Computer Approach." In O.M. Jenson, D.M. Parkin and R. MacLennan, eds., Cancer Registration Principles and Methods (pp. 246-57). Lyon, France: IARC Publications.

Cohen, J., J. Bilsen, P. Hooft, P. Deboosere, G. Wal and L. Deliens. 2006. "Dying at Home or in an Institution Using Death Certificates to Explore the Factors Associated with Place of Death." Health Policy 78(2-3): 319-29. 
Deyo, R.A., D.C. Cherkin and M.A. Ciol. 1992. "Adapting a Clinical Comorbidity Index for Use with ICD-9-CM Administrative Databases." Journal of Clinical Epidemiology 45(6): 613-19.

Earle, C.C. and J.Z. Ayanian. 2006. "Looking Back from Death: The Value of Retrospective Studies of End-of-Life Care." Journal of Clinical Oncology 24(6): 838-40.

Earle, C. C., B.A. Neville, M.B. Landrum, J.Z. Ayanian, S.D. Block and J.C. Weeks. 2004."Trends in the Aggressiveness of Cancer Care Near the End of Life." Journal of Clinical Oncology 22(2): 315-21.

Earle, C.C., B.A. Neville, M.B. Landrum, J.M. Souza, J.C. Weeks, S.D. Block, E. Grunfeld and J.Z. Ayanian. 2005. "Evaluating Claims-Based Indicators of the Intensity of End-of-Life Cancer Care." International Journal of Quality Health Care 17(6): 505-09.

Earle, C.C., E.R. Park, B. Lai, J.C. Weeks, J.Z. Ayanian and S. Block. 2003. “Identifying Potential Indicators of the Quality of End-of-Life Cancer Care from Administrative Data." Journal of Clinical Oncology 21(6): 1133-38.

Ferris, F.D., H.M. Balfour, K. Bowen, J. Farely, M. Hardwick, C. Lamontagne et al. 2002. A Model to Guide Hospice Palliative Care: Based on National Principles and Norms of Practice. Ottawa:

Canadian Hospice Palliative Care Association.

Flory, J., Y.X. Yinong, I. Gurol, N. Levinsky, A. Ash and E. Emanuel. 2004. "Place of Death: US Trends Since 1980." Health Affairs (Millwood) 23(3): 194-200.

Foreman, L.M., R.W. Hunt, C.G. Luke and D.M. Roder. 2006. "Factors Predictive of Preferred Place of Death in the General Population of South Australia." Palliative Medicine 20(4): 447-53.

Gagnon, B., N.E. Mayo, J. Hanley and N. MacDonald. 2004. "Pattern of Care at the End of Life: Does Age Make a Difference in What Happens to Women with Breast Cancer?" Journal of Clinical Oncology 22(17): 3458-65.

Gilbar, O. and M. Steiner. 1996. "When Death Comes: Where Should Patients Die?” Hospital Journal 11(1): 31-48.

Gomes, B. and I.J. Higginson. 2006. "Factors Influencing Death at Home in Terminally Ill Patients with Cancer: Systematic Review." British Medical Journal 332(7540): 515-21.

Grande, G.E., J.M. Addington-Hall and C.J. Todd. 1998. "Place of Death and Access to Home Care Services: Are Certain Patient Groups at a Disadvantage?" Social Science E Medicine 47(5): 565-79.

Grande, G.E., C.J. Todd, S.I. Barclay and M.C. Farquhar. 2000. "A Randomized Controlled Trial of a Hospital at Home Service for the Terminally Ill." Palliative Medicine 14(5): 375-85.

Grunfeld, E., L. Lethbridge, R. Dewar, B. Lawson, L.F. Paszat, G. Johnston, F. Burge, P. McIntyre and C.C. Earle. 2006."Towards Using Administrative Databases to Measure Population-Based Indicators of Quality of End-of-Life Care: Testing the Methodology" Palliative Medicine 20(8): 769-77.

Heyland, D.K., J.V. Lavery, J.E. Tranmer, S.E. Shortt and S.J. Taylor. 2000. “Dying in Canada: Is It an Institutionalized, Technologically Supported Experience?” Journal of Palliative Care 16(Suppl.): S10-S16.

Huang, J., C. Boyd, S. Tyldesley, J. Zhang-Salomons, P.A. Groome and W.J. Mackillop. 2002. "Time Spent in Hospital in the Last Six Months of Life in Patients Who Died of Cancer in Ontario." Journal of Clinical Oncology 20(6): 1584-92. 
Hughes, S.L., J. Cummings, F. Weaver, L. Manheim, B. Braun and K. Conrad. 1992."A

Randomized Trial of the Cost Effectiveness of VA Hospital-Based Home Care for the Terminally Ill." Health Services Research 26(6): 801-17.

Institute of Medicine. 2001. Improving Palliative Care for Cancer. Washington, DC: National Academy of Sciences.

Jordhoy, M.S., P. Fayers, T. Saltnes, M. Ahlner-Elmqvist, M. Jannert and S. Kaasa. 2000. “A PalliativeCare Intervention and Death at Home: A Cluster Randomised Trial." Lancet 356(9233): 888-93.

Kane, R.L., J. Wales, L. Bernstein, A. Leibowitz and S. Kaplan. 1984. "A Randomised Controlled Trial of Hospice Care." Lancet 1(8382): 890-94.

Karlsen, S. and J. Addington-Hall. 1998. "How Do Cancer Patients Who Die at Home Differ from Those Who Die Elsewhere?" Palliative Medicine 12(4): 279-86.

Kirby, M.J.L. and M. LeBreton. 2002. The Health of Canadians - The Federal Role. Volume Six: Recommendations for Reform. Ottawa: Senate Standing Committee on Social Affairs, Science and Technology.

McWhinney, I.R., M.J. Bass and V. Orr. 1995. "Factors Associated with Location of Death (Home or Hospital) of Patients Referred to a Palliative Care Team." Canadian Medical Association Journal 152(3): 361-67.

Ontario Ministry of Health and Long-Term Care (MoHLTC). 2005 (October 4)."McGuinty Government Improving End-of-Life Care. Strategy Will Enhance Services in Homes and Hospices." News release. Retrieved January 8, 2010. <http://www.health.gov.on.ca/english/media/ news_releases/archives/nr_05/nr_100405.html >.

Ontario Ministry of Health and Long-Term Care (MoHLTC). 2007. Ontario's Local Health Integration Networks. Retrieved January 8, 2010. <http://www.lhins.on.ca/home.aspx>.

Patrick, D.L., J.R. Curtis, R.A. Engelberg, E. Nielsen and E. McCown. 2003."Measuring and Improving the Quality of Dying and Death." Annals of Internal Medicine 139(5 Pt. 2): 410-15.

Pritchard, R.S., E.S. Fisher, J.M. Teno, S.M. Sharp, D.J. Reding, W.A. Knaus, J.E. Wennberg and J. Lynn. 1998. "Influence of Patient Preferences and Local Health System Characteristics on the Place of Death. SUPPORT Investigators. Study to Understand Prognoses and Preferences for Risks and Outcomes of Treatment." Journal of the American Geriatric Society 46(10): 1242-50.

Rabow, M.W., S.L. Dibble, S.Z. Pantilat and S.J. McPhee. 2004."The Comprehensive Care Team: A Controlled Trial of Outpatient Palliative Medicine Consultation." Archives of Internal Medicine 164(1): 83-91.

Raftery, J.P., J.M. Addington-Hall, L.D. MacDonald, H.R. Anderson, J.M. Bland, J. Chamberlain and P. Freeling. 1996. "A Randomized Controlled Trial of the Cost-Effectiveness of a District Co-ordinating Service for Terminally Ill Cancer Patients." Palliative Medicine 10(2): 151-61.

Robles, S.C., L.D. Marrett, E.A. Clarke and H.A. Risch. 1988. "An Application of CaptureRecapture Methods to the Estimation of Completeness of Cancer Registration." Journal of Clinical Epidemiology 41(5): 495-501.

Romanow, R.J. 2002. Building on Values: The Future of Health Care in Canada. Saskatoon: Commission on the Future of Health Care in Canada.

Setoguchi, S., C.C. Earle, R. Glynn, M. Stedman, J.M. Polinski, C.P. Corcoran and J.S. Haas. 2008. "Comparison of Prospective and Retrospective Indicators of the Quality of End-of-Life Cancer Care." Journal of Clinical Oncology 26(35): 5671-78. 
Statistics Canada. 1994. Coverage, 1991 Census Technical Reports. Ottawa: Minister of Industry, Science and Technology.

Stewart, A.L., J. Teno, D.L. Patrick and J. Lynn. 1999. “The Concept of Quality of Life of Dying Persons in the Context of Health Care." Journal of Pain and Symptom Management 17(2): 93-108.

Teno, J.M., B.R. Clarridge, V. Casey, L.C. Welch, T. Wetle, R. Shield and V. Mor. 2004. “Family Perspectives on End-of-Life Care at the Last Place of Care." Journal of the American Medical Association 291(1): 88-93.

Teno, J.M. and V. Mor. 2005. "Resurrecting Treatment Histories of Dead Patients." Journal of the American Medical Association 293(13): 1591.

Wilkins, R. 2001. PCCF + Version 3G Users Guide: Automated Geographic Coding Based on the Statistics Canada Postal Code Conversions Files. Ottawa: Statistics Canada.

Wilson, D.M., C.D. Truman, R. Thomas, R. Fainsinger, K. Kovacs-Burns, K. Froggatt and C. Justice. 2009. "The Rapidly Changing Location of Death in Canada, 1994-2004." Social Science E Medicine 68(10): 1752-58.

Zimmer, J.G., A. Groth-Juncker and J. McCusker. 1985. "A Randomized Controlled Study of a Home Health Care Team." American Journal of Public Health 75(2): 134-41. 